\title{
EDITORIAL
}

\section{INVESTIGACIÓN EN SALUD LABORAL, UNA TAREA PENDIENTE}

\begin{abstract}
e destacan en este número trabajos en el ámbito de la Salud Laboral. Esta área $\checkmark$ de investigación es aún incipiente como línea de investigación en enfermería en el país, aunque nuestra profesión es fuente de preocupación e indagación de otras disciplinas por los problemas que emergen del quehacer que realizan las enfermeras, sus riesgos y condiciones de trabajo que en algunos sectores son muy precarios. Una muestra es el burnout; el stress laboral y los efectos de los turnos que han sido ampliamente documentados por investigadores del ámbito de la psicología del trabajo. No obstante, desde la enfermería, se reconoce la generación de conocimiento en esta línea como una tarea pendiente a nivel nacional. La investigación en salud laboral respecto a la magnitud y los determinantes de los problemas de salud que padecen los trabajadores es claramante insuficiente. Es, por tanto, un terreno amplio y fértil para nuevas pesquisas. Este conocimiento, es un requisito básico para superar las limitaciones del sistema de seguridad y salud en el trabajo y donde la enfermería puede colaborar aportando variada información que signifique mejorar estos espacios.
\end{abstract}

Se evidencian temas emergentes que pueden ser motivadores de pesquisas y servir de inspiración a los investigadores de enfermería como son: la relación género y trabajo; condiciones de trabajo de la población emigrante; trabajo infantil; calidad de vida y trabajo; promoción de la salud en el lugar de trabajo, entre otras.

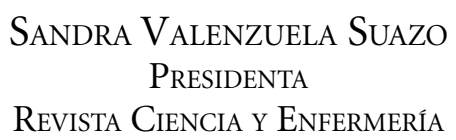

